Igor Kozymenko ${ }^{1}$

\title{
MODELING OF STATE REGULATION OF THE COAL INDUSTRY OF UKRAINE IN THE CONTEXT OF STRUCTURAL TRANSFORMATIONS OF THE NATIONAL ECONOMY
}

Keywords: public administration, coal industry, model, project, transformation, resource potential, strategy.

ABSTRACT: The article is devoted to the state regulation of the processes of modeling of the development of the coal industry of Ukraine in the context of structural transformations of the national economy. An important task of modern science of public administration is to provide systematic methods of substantiation of public administration decisions to determine the vector of development of society as a whole and individual sectors of the national economy, which actualizes the formation of a model of justification of coal industry development strategy. It is proved that the effectiveness of the organizational mechanism of state regulation is ensured through a transparent system of control over changes in the technical and economic parameters of the coal industry of Ukraine. The author proposes the formation of an appropriate tool for programming effective change within a certain cyclical nature of the industry. Systematized information on strategies relevant to planning of the development of the coal industry and the mining sector as a whole. Analytically interpreted information of the optimal plan by the method of dynamic programming using recurrent Bellman equations is presented. The optimal plan of tactical actions at formation of strategy of development of the coal industry in a cycle of a mining and industrial complex is defined. The comparison of the optimal plan with possible alternative actions of the management staff of the coal industry is carried out. The perspective plan of tactical actions through priority use of projects of the maximum profitability at formation of strategy of development of the coal industry in a cycle of a mining and industrial complex is

1 Postgraduate Student at the Department of Economic Policy and Governance, National Academy of Public Administration under the President of Ukraine, iakoz@ukr. net. ORCID: 0000-0003-0733-5121. 
presented. The plan of tactical actions through priority support of projects of preservation of a current condition at formation of strategy of development of the coal industry in a cycle of a mining and industrial complex is presented. The optimal plan of tactical actions in forming the strategy of coal industry development in the cycle of mining complex with good initial state of resource potential, with probable highest level of initial state of resource potential, with unsatisfactory initial state of resource potential is presented. It is proved that the current critical state of the resource base of coal mining provokes the emergence of natural irrational behavior in Ukraine, when the crisis focuses only on economic benefits without proper management of resource potential, which emphasizes the importance of public administration in resource management in crisis development programs of the coal industry. The developed methodology provides the best solution to the two-criteria problem of public administration of the coal industry: the implementation of public administration functions, including economic, and providing conditions for sustainable efficient resource use.

\section{INTRODUCTION}

An important task of public administration science is to provide systematized methods of substantiation of public administration decisions to determine the vector of development of society as a whole and individual sectors of the national economy, which actualizes the formation of methods (models) of substantiation of coal industry development strategy. The effectiveness of the organizational mechanism of state regulation is ensured through a transparent system of control over changes in the technical and economic parameters of the coal industry, for example, through the formation of an indicative planning system. (Amosha A.I., Zaloznova Ju. S., Cherevatskij D., 2017). Therefore, to implement this requirement, it is proposed to form an appropriate tool for programming effective change within a certain cyclical nature of the industry. The methodological basis of this tool is the methodology of dynamic programming according to the Bellman principle (Badaljan L., 2008, Piskulova N., 2010, Soldak M.A., 2012). An additional advantage of setting indicative planning using dynamic programming is the attitude to the links of the development cycle as dynamic systems with different variants of change as the current economic result to ensure the implementation of the economic function of public administration and to reflect the transfer principle of resource management. 
The purpose of the article is to present the models of coal industry development in the context of structural transformations of the national economy.

\section{MODELING OF THE DEVELOPMENT OF THE COAL INDUSTRY}

To ensure the conditions for mathematical modeling of the cyclical development of the coal industry, we assume that the state of the investment potential of the resources of sustainable development of the state is changing not continuously but discretely. Due to the fact that the usefulness (or productivity) of resources is determined on the basis of multifactor dependence, there are a certain range of variations. Note that if we accept the continuity of the state of resource potential, it is logical to accept the continuity of management options, ie to recognize that they belong to countless sets, which will not allow to find a solution. Innumerability does not give a clear idea of the modeled processes. Thus, discreteness means the following: there is some limited space within which the state of resource potential can be taken as a constant. This means that it is possible to be limited to a certain range of changes in resource potential, within which there are discrete levels that correspond to a certain state. These levels regulate these states, in the sense that the "best" state of resource potential corresponds to greater efficiency, and in a fixed price - less costly production activities.

In relation to the options for management strategies, the assumption is different. In real conditions, their number is limited, but quite numerous. They are based on investment projects for the development of the coal industry and other sectors of the national economy, which implement certain innovations in the implementation of certain resources of the industry. However, for an illustrative example, the number of technologies must be limited, because otherwise the clarity of the experiment is lost. In this regard, 4 strategies for the development of sectors of the national economy for each stage of the cycle, starting with the coal industry. For the 4 stages of the cycle, this is 16 large-scale projects that reflect the direction of development. 
Therefore, the source information is presented as follows. The development cycle of the coal industry is represented by four industries integrated with product logistics: coal industry, chemical industry (activities related to the use of coal as an energy resource or raw material), metallurgy (same principle, but through chemical production), mechanical engineering (activities related to the production of coal mining equipment). The cost of economic activity, due to the use of a single resource base (personnel, finance, technology, etc.), depends on the state of resource potential of development. We accept 4 levels of resource potential of development: $S$ (1) - the highest, S (4) - the lowest. In order to reflect the dependence of efficiency on the state of resource potential of development, we accept the assumption, that, although simplifies the real processes, but gives them clarity in terms of computational procedures and the mechanism of finding the optimal planning strategy. Suppose that the efficiency of the activity in the best condition of the resource potential of development is known. It has an index of 1 . Then the next level 2 - corresponds to a twofold increase in the level of variable costs, which leads to a decrease in efficiency. And the worst state of resource provision of development conditions - 4 has a volume of variable costs, 4 times more than under the best conditions of resource provision. Thus, the total amount of costs for each industry can be represented as a linear function, where the free coefficient determines the amount of conditionally fixed costs, which does not depend on the state of resource development; the coefficient at the variable reflects the reaction of the production system of industry to changes in the state of resource provision. Using the basic economic parameters of the functioning of industries in the system of mining and industrial complex (hereinafter MIC), calculated cost models that affect efficiency:

Machine-building industry cost model $\mathrm{Cmbi}=2.58+0.448{ }^{*} \mathrm{~S}$

Metallurgy cost model Cmet $=1,56+0,592 * S$

Chemical industry cost model Cchem $=1.81+0.175 * \mathrm{~S}$

Coal industry cost model of the $\mathrm{CvdB}=1,153+0,161 * S$

It is important to note that both costs and revenues were related to a single unit of focus. As part of planning the development of the coal 
industry, calculations should be made in terms of 1 ton of coal as a unit of conventional raw materials. Reactivity in the cost model is determined by the cost-effectiveness of the sensitivity of the adopted technology of production activities to changes in the cost of coal as a raw material or energy resource.

Let us now consider the initial data relating to development strategies. The main task to be solved in accordance with the adopted methodology is to model the links between the adopted strategy and its impact on the state of resource development potential. In the developed algorithmic implementation, this connection is manifested through the transformation of production functions. Here, for clarity, these dependencies are simplified in order to be able to operate with those states that are accepted above. This means that if a certain strategy is used, it must transfer the current state to another, but in such a way that the new state is one of the four selected above. Suppose, for example, that using a certain technology, the state of resource potential has improved by 1 level. It means that if the previous state was characterized as good (level $=2$ ), then the new state will be - better (level =1). Above this level, the condition cannot be improved. This restriction is quite real. Thus, if the strategy -2 is used for the initial 2 , then the final state will be 1 , but not less (by analogy with the rank). Similarly, the state of resource potential of development cannot be below 4 rank. This means that for a state of 3 , the use of a "destructive" strategy, which is evaluated as +2 , gives a final state equal to 4 rank, but not 5. Finally, each strategy corresponds to a certain level of profitability, which is determined by the product set of the main and by-products obtained from the use and processing of coal.

The adopted cycle functions as follows: Stage 1 - the obtained technical and technological conditions of mining engineering form the conditions for the formation of the efficiency of coal mining; Stage 2 - the efficiency of obtaining coal products creates the conditions for changing the efficiency of the relevant branches of the chemical industry; Stage 3 - the efficiency of chemical industries related to metallurgical production creates the conditions for changing the efficiency of the metallurgical industry; Stage 4 - the efficiency of production of metallurgical raw materials creates the conditions for changing the efficiency of mechanical engineer- 
ing technologies; Stage 5 - the implementation of innovative progress in mechanical engineering creates the conditions for further development and so on. The latest initial information is related to the initial state of the system. The statement of the problem is known: it is necessary to calculate at what stage which strategy to choose to get the maximum economic efficiency for one cycle of development of the coal industry. This period is taken for clarity, due to the complexity of building schedules. Note that with such limited information, in principle, you can go through all the options and choose the best.

Using this input information, alternatives of events are calculated depending on the options of tactical actions within the MIC, as a model of the development cycle of the coal industry. We present analytically interpreted information of the optimal plan by the method of dynamic programming using recurrent Bellman equations. The initial state of resource potential, which reflects the current potential of the coal industry, is assessed as satisfactory (level-rank $=3$ ), ie the presence of significant reserves of explored coal reserves in the subsoil (environmental resource), but there is a difficult social situation with degradation of skilled workers, the state of technical support is complex without a corresponding innovative update. Regarding the dynamics of change of this state, the optimal plan determines its improvement with the achievement of the highest level (rank =1) at the 3rd stage. But the cycle ends with the second level of the resource potential of the MIC. This can be explained by the greater usefulness of economic efficiency at the last stage, because mechanical engineering is a concentrator of significant cost pressure in the presented complex. At this stage, there is a closing of the cycle of the appropriate order and the transfer of technical means to increase efficiency in cost management of the coal industry of the next cycle. Note that in contrast to the transferring market mechanism of all stages of the development cycle, when costs are fully transferred to the cost of production, engineering products are distributed to consumer products gradually over a period of time, for example, in the form of depreciation. This must be taken into account when designing a multi-cycle system for planning the development of the coal industry within the MIC.

The use of the first local strategy for the development of mechanical engineering reduces the resource potential to an acceptable level and 
ensures the manufacture of affordable equipment for the coal industry. The use of the second local strategy for the development of the chemical industry provides support for the state of resource potential and, which ensures the receipt of affordable chemical raw materials for metallurgy. The use of the third local strategy of metallurgy development provides an increase to the highest level of resource potential and reduce the cost of metal smelting, which ensures the availability of available metal for mechanical engineering. The use of the fourth local strategy for the development of the coal industry provides an increase in the level of resource potential and reduce the cost of coal production, which provides cheaper coal for chemical processing.

The next stage of the study is to compare the optimal plan with possible alternative actions of the management of the coal industry. The apparatus of public administration in determining the prospects for the development of the coal industry is guided by a number of priorities in the choice of actions that, in their opinion, create the preconditions for maximizing socio-economic performance and/or maintaining the welfare of the population.

The main argument in the development of the state policy for the management of the national economy is the need to create an appropriate investment environment as a prerequisite for business activity of market participants. The economic mechanisms established by the subjects form the conditions for effective and efficient development, which contributes to the formation of reserves for the implementation of social functions by the state. Therefore, we simulate a situation where public administration will be guided by market priorities when determining local strategies for the development of MIC industries.

Localization of economic efficiency gives the effect of economic efficiency of each of the industries, but creates the conditions for reducing the efficiency of the MIC in particular, and the national economy in general. Thus, the market mechanism ensures the efficiency of the independent functioning of national economic entities, but destroys the effect of integration. The complex becomes only a set of enterprises, which contradicts the state task of ensuring sustainable development of the national economy. 
Thus, the effectiveness of the proposed method of determining the strategy of development of the coal industry within the MIC, as a model of the development cycle of the coal industry, in comparison with the market principles of strategic management is proven.

Other priorities are guided by public officials in the conditions of limited means of realization of resource potential, ie in the conditions of realization of anti-crisis programs. This behavior can be modeled by maintaining the current state of the MIC. This plan similarly ensures the economic efficiency and effectiveness of the MIC industries, at a higher level than the previous alternative to the optimal plan. In addition, it should be noted that the obtained data prove the fact that the effective development of the coal industry and the preservation of the synergy effect from the organization of the integrated system of MIC requires additional resources. Significant resource potential of the complex is spent on the formation of economic efficiency of industrial systems, thereby unbalancing the overall resource base. Thus, the effectiveness of the proposed method of determining the strategy of development of the coal industry within the MIC, as a model of the development cycle of the coal industry, in comparison with the regime of crisis management of the national economy - is proven. On the other hand, the availability of opportunities and reserves forms the priorities for increasing national wealth through the growth of the resource fund. Such behavior can be modeled by the mode of restrained growth of the state of the MIC. The plan of tactical actions through priority support of development of resource potential at formation of strategy of development of the coal industry in a cycle of MIC is presented.

This plan can be characterized by the lowest overall economic efficiency. This situation can be explained by the fact that under the accepted conditions the means of providing the conditions for increasing of the resource potential are too «expensive». Obviously, this situation can be corrected in the next cycle, but in this case they are unjustified for the coal and chemical industries. This situation can be remedied by providing state support for resource-saving measures and measures to increase the potential of the resource fund. For example, within the social resource, which is the basis of qualified personnel, support for measures to increase the 
potential of social resources means providing conditions for the growth of professionalism and skills, providing living conditions as a preventive measure of staff degradation.

Thus, the effectiveness of the proposed method of determining the strategy of development of the coal industry within the MIC, as a model of the cycle of development of the coal industry, in comparison with the mode of management of restrained growth of the resource fund is proved. Along with alternative technologies of public administration, it is necessary to determine how the effectiveness and efficiency of the MIC, as a model of the development cycle of the coal industry, is influenced by the initial state of the system. The optimal plan allows to obtain a good condition from the tax satisfactory state of resource potential at the end of the cycle. We model the further situation within the second cycle of development of the coal industry.

It is noteworthy that the efficiency of the stages of industrial production in this case goes beyond the accepted framework for modeling the efficiency of industries. This proves the previously mentioned fact of the need for price balancing of the economic mechanism of the industrial sector of the economy. Note that the achievement of maximum potential is limited by the influence of local development strategies at the stage of mechanical engineering. Therefore, the highest level can be realized only through their review. The modeling of the optimal plan of tactical actions at formation of strategy of development of the coal industry in a cycle of MIC with probable highest level of an initial condition of resource potential is presented. Thus, the highest level of resource management ensures the highest efficiency of management at all stages of the cycle.

On the other hand, if we take into account that the assessment of the current state of development of the coal industry in particular and the MIC in general could be too optimistic, we can model the optimal plan according to the developed methodology with unsatisfactory initial state of resource potential. The peculiarity of this plan is the optimal behavior at the stage of determining the local strategy for the development of the coal industry. The critical state of the resource basis of economic activity of coal mining provokes the emergence of natural irrational behavior, when the crisis situation focuses only on obtaining economic benefits 
without proper management of resource potential. These circumstances highlight the special importance of public administration in the management of resource potential in the framework of anti-crisis programs for the development of the coal industry.

Thus, we can conclude that the developed methodology provides the best solution to the two-criteria problem of public administration of the coal industry: the implementation of the economic function of public administration and ensuring conditions for sustainable efficient use of resources.

\section{CONCLUSION}

Taking into account the results obtained from modeling of the development of the coal industry in the MIC, we note that crisis prevention in connection with the restructuring of the energy sector of the national economy is possible only if the role of the coal industry in the long-term strategy of national economy is relevantly defined. The current course of Ukraine can be described as a priority strategy for the greening of sectors of the national economy, which is manifested in the predominant protectionism of investment initiatives in the field of environmental energy. Coal generation is a forced solution in the conditions of formation of capacities of renewable energy sources and shortage of gas fuel. The progress of the adopted strategy is based on the destruction of the coal industry. This is a sharp contradiction in what is done and why: «for the sake of saving the recipient, we sacrifice the life of the donor.»

The basis of a balanced decision on the prospects for the development of the coal industry is to determine the impact of alternatives on the overall result. The main expectations of compensation for the loss of the coal industry by the state administration are placed on coal imports. Imports will change the economic conditions for the functioning of industries in the MIC and will manifest itself in reducing the efficiency of technology in the current market conditions or raising prices in many areas of the economy to ensure acceptable profitability. This will significantly affect the sustainability of the national economy and the quality of 
life of the population, but will ensure the preservation of the industrial sector without the domestic coal industry.

However, as defined earlier, public administration is focused on providing conditions for the realization of the investment potential of economic, social and environmental resources, which in alternative options for providing products of the coal industry lose value. A blow to all components of sustainable development of the state economy will lead to the development of a protracted crisis. Thus, the scenario of development of the national economy with the narrowing of the role of the domestic coal industry should have a priority plan to change the investment potential of economic, social and environmental resources involved in the coal industry. And this should not be compensatory in nature for the preservation of social resources, but as a constructive plan for the restructuring of the national and regional economy.

Regarding the organization of an effective system of state management of the coal industry, in the framework of determining the structure of subordination and partnership, it is necessary to be guided by the compatibility of goals and ways to achieve results. The current place of the management system of the coal industry is closely connected with energy specialization and is involved in the system of priorities of the energy sphere, the development strategy of which is characterized by priority environmental orientation. Thus, the intersectoral links of the coal industry with the chemical, fuel, metallurgical and machine-building industries lose their significance. This is a narrow view of the resource potential of the national economy. Therefore, in determining the measures to optimize the management system, the logistics links of the coal industry should be of paramount importance. Subordination to the strategic goals of the national economy can be realized only through the restructuring of the logistics of the industrial system. 


\section{BIBLIOGRAPHY:}

Amosha, A.I., Zaloznova Ju, S., Cherevatskij, D. (2017). Ju. Ugol'naja promyshlennost' i gibridnaja jekonomika [Coal industry and hybrid economy]: monogr. Kyi'v: NAN Ukrainy, In-t jekonomiki prom-sti.

Badaljan, L. (2008). Tehnologicheskij perelom nachala veka i interesy Rossii [Technological change of the beginning of the century and the interests of Russia] / L. Badljan, V. Krivorotov // Jekonomicheskie strategii. No. 3. pp. 12-19.

Piskulova, N. (2010). Razvitie mirovoj jekonomiki: jekologicheskij vektor [Development of the world economy: ecological vector]. Mirovaja jekonomika i mezhdunarodnye otnoshenija. No. 12.pp. 28-37.

Soldak, M.A. (2012). Zabroshennye territorii («brownfields») v gorodskoj strukture: problemy upravlenija i napravlenija jeffektivnogo ispol'zovanija [Abandoned territories («brownfields») in the urban structure: management problems and directions for effective use]. Visnik Shidnoukraïns'kogo nacional'nogo universitetu im. Volodimira Dalja. No. 11 (182). pp. 456-462.

Shabanova, M.A. (2006). Sociojekonomika: ot paradigmy k novoj nauke [Socioeconomics: from a paradigm to a new science]. Obshhestvennye nauki i sovremennost'. № 1. pp. 121-133.

Ki-Jong Woo. Korea's (2011). Fast-Moving Strategy on Green Growth. IGES, Feb. 2011. Downloaded from: http://www.iges.or.jp/en/news/topic/asianfocus201102.html

Sachs, J., Tubiana, L. (2014). Sustainable Development Solutions Network (SDSN) and Institute for Sustainable Development and International Relations (IDDRI). September. Downloaded from: http://unsdsn.org/wp-ontent/uploads/2014/09/DDPP 2014 report Canada chapter.pdf 